Tropical Journal of Pharmaceutical Research October 2012; 11 (5): 703-712

(C) Pharmacotherapy Group, Faculty of Pharmacy, University of Benin

Benin City, 300001 Nigeria.

All rights reserved.

Available online at http://www.tjpr.org http://dx.doi.org/10.4314/tjpr.v11i5.2

Research Article

\title{
Development and Evaluation of Chronotherapeutic Drug Delivery System for the Management of Nocturnal Asthma
}

\author{
Javed Qureshi ${ }^{1,2^{*}}$, Javed Ali ${ }^{1}$, Sanjula Baboota ${ }^{1}$, Alka Ahuja ${ }^{1}$ and Chitneni \\ Mallikarjun ${ }^{2}$ \\ ${ }^{1}$ Department of Pharmaceutics, Jamia Hamdard (Hamdard University), New Delhi, India, ${ }^{2}$ Department of \\ Pharmaceutical Technology, International Medical University, Kuala Lumpur, Malaysia
}

\begin{abstract}
Purpose: To develop an oral capsule-based chronomodulated drug delivery system of salbutamol sulphate for the treatment of nocturnal asthma.

Methods: The basic design of the proposed dosage form entails an insoluble cross-linked capsule body filled with drug-loaded pellets sealed with hydrocolloid plug and a soluble capsule cap. Various hydrocolloid polymers, namely, hydroxypropyl methylcellulose, (HPMC), hydroxypropyl cellulose (HPC), sodium alginate, polyethylene oxide (PEO) and guar gum. were used to optimize the plug material in the delivery in order to modulate lag period To avoid gastric transit time variability, the entire system was coated with Eudragit S100/Eudragit L100 dispersion (4:1), an enteric polymer system that dissolves at pH 6.8.

Results: Time-specific pulsatile release with $4 \mathrm{~h}$ lag period was achieved with crosslinked insoluble gelatin capsule shells containing pellets prepared from Avicel PH 101/lactose (80: 10) and $3 \%$ Acidisol as disintegrant. In vitro data indicate that the developed pulsatile system released almost $98 \%$ of the drug shoertly after the predetermined lag time of $4 \mathrm{~h}$.

Conclusion: The developed system is capable of releasing the drug after a 4-h lag period. However, in vivo studies need to be carried out to ascertain the effectiveness of the formulation.
\end{abstract}

Keywords: Time controlled, pH-controlled, Lag time, pulsed release, Hydrocolloid plug, Nocturnal asthma 


\section{INTRODUCTION}

In the last two decades, studies on chronopharmacokinetic and chronopharmacodynamic parameters of various drugs gave convincingly evidence that paradigm of older "Homeostasis theory (constancy of milieu interne)" cannot be sustained any longer [1]. It is now well documented that most of the physiological functions of an organism display a natural synchronization with an internal 24-h rhythmic clock (circadian rhythm) which is controlled by sleep wake cycle. Few of the physiological processlikes such as lung function, heart rate, body temperature, liver function, blood flow and hormonal release, exhibit a peak time of functionality that is in accordance with these rhythmic cycles [2]. Diseases associated with the above physiological functions, including bronchial asthma, hypertension, myocardial infarction, angina pectoris, rheumatic disorders and ulcers, exhibit peak time of activity of function within a circadian rhythm [3].

Asthma is one of the most common ailments with the largest circadian variation [4]. It is a disease of lung airways (bronchi) characterized by hyper-responsiveness to a variety of stimuli $[5,6]$. Nocturnal asthma is defined as a variable nighttime exacerbation of the underlying asthma condition associated with increased airway responsiveness and worsening of lung functions [7]. The lung function (peak expiratory flow rate, $\mathrm{FEV}_{1}$ ) is usually highest at $4 \mathrm{pm}$ and lowest at $4 \mathrm{am}$. Generally, asthma attacks are more prevalent in early morning [8]. It is inconvenient for a patient to take medicine at midnight. In this condition, a drug delivery system that can release the drug at a predetermined time to guarantee therapeutic efficacy is a prerequisite. This can be achieved by developing a pulsed release system capable of delivering the drug at the required time after a well-defined lag time [9-12].
Multi-particulate systems are a better way of obtaining well-controlled regulation of drug release from oral dosage forms due to reduced risk of dose-dumping and reproducibility in release profile than the single unit systems [13-15].

The objective of this study was to develop a capsule system based on chronopharmaceutical approach for the treatment of nocturnal asthma using salbutamol sulphate as a model drug. The aim was to have a lag time of $4 \mathrm{~h}$, i.e., the system is to be taken at bed time $(10 \mathrm{pm})$ and is expected to release the drug after a period of 4 h, i.e., at 2 am. Literature evidence shows that the peak plasma concentration of salbutamol sulphate is reached approximately $2 \mathrm{~h}$ after oral administration. Therefore, the drug concentration would be at its maximum level, when asthma attacks are more prevalent, i.e., at $4 \mathrm{am}$.

\section{EXPERIMENTAL}

\section{Materials}

Salbutamol sulphate (Ranbaxy Research Laboratories, Gurgaon, India), microcrystalline cellulose (Avicel PH101 and PH 102, Jubiliant Organosys, New Delhi India), Eudragit L 100 and S 100 (Rohm Pharma, $\mathrm{GmbH}$ Germany) sodium alginate (SA), Hydroxypropyl methylcellulose (HPMC), hydroxypropyl cellulose (HPC), polyethylene oxide (PEO), ethylcellulose (EC) (Ranbaxy Research Laboratories, Gurgaon, India) were obtained as gifts from the suppliers. Lactose and dicalcium phosphate (DCP) were purchased from DKSH, India. All other chemicals used were of analytical grade and obtained from authentic suppliers.

\section{Development of cross-linked gelatin capsule body}

In order to prepare insoluble gelatin capsule body, commercial empty gelatin capsule shells were exposed to formalin vapors generated by a reaction of $15 \% \mathrm{v} / \mathrm{v}$ 
formaldehyde solution with potassium permanganate. The caps of the capsules were not subjected to this treatment leaving them water soluble. The treatment was allowed to continue for $12 \mathrm{~h}$ followed by drying at $45{ }^{\circ} \mathrm{C}$ for $1 \mathrm{~h}$ and then at ambient temperature to remove residual formaldehyde. The cross-linked capsules shells were checked manually for any visual defects such as dimension, shape, pinholes etc. Solubility studies for cross-linked capsule shell were carried out in water, $0.1 \mathrm{M} \mathrm{HCl}$ and phosphate buffer. A beaker containing $100 \mathrm{ml}$ of the medium and cross-linked capsule shells was placed in a shaker system and shaken for $24 \mathrm{~h}$. The capsules were capped with water-soluble caps and stored in air-tight containers until used [16].

\section{Limit test for free formaldehyde}

The method reported by Mastiholimath et al [17] was used for this test. The reference solution used was $0.002 \mathrm{w} / \mathrm{v}$ formaldehyde solution. The test solution was prepared by soaking 25 formaldehyde treated capsule bodies in distilled water and stirred for $1 \mathrm{~h}$ with a magnetic stirrer to dissolve the free formaldehyde. The resulting solution was filtered, washed with distilled water and diluted to ten times with the washings. One milliliter of this test solution was taken into a test tube, mixed with $5 \mathrm{ml}$ of acetone reagent and the volume adjusted to $10 \mathrm{ml}$ with distilled water. The mixture was warmed at $40{ }^{\circ} \mathrm{C}$ for $30 \mathrm{~min}$ over a water bath. The color intensity of the test solution was compared with that of the reference solution prepared in a similar manner using standard formaldehyde solution. To pass the test, the color intensity of the test solution should not be greater than that of the standard solution.

\section{Preparation of rapidly disintegrating pellets}

Rapidly disintegrating pellets were prepared by extrusion-spheronization method based on the composition in Table 1. Various combinations of microcrystalline cellulose
(MCC), dicalcium phosphate (DCP) and lactose were studied as diluents for the preparation of the pellets In order to achieve rapid release of the drug from the pellets, $3 \%$ AcDiSol (croscarmellose sodium) was added as a super-disintegrant to the formulation. All the ingredients were sieved through $425 \mu \mathrm{m}$ screen and blended in a double-cone blender (Bhagwati Pharma machinery, India). Two percent PVP K-30 aqueous solution, as binding agent, was added and the mixture kneaded manually. The wet mass obtained was extruded through a $1.2 \mathrm{~mm}$ screen. The extrudate was spheronized for $3 \mathrm{~min}$ in spheronizer (Caleva MBS, UK)operating at 800 - $1100 \mathrm{rpm}$. The pellets obtained were dried at $50{ }^{\circ} \mathrm{C}$ for $24 \mathrm{~h}$ in an oven and then sized through 1180 and $850 \mu \mathrm{m}$ sieve, respectively.

\section{Evaluation of pellets}

The pellets were evaluated for various physical parameters such as particle size distribution, bulk density, friability, flow properties and content uniformity as per standard procedure. Particle size was determined by sieve shaker method using sieves of different mesh sizes. Flow properties and content uniformity were evaluated as per the methods described in United State Pharmacopoeia 24 Shape and surface characteristics of the pellets were determined by scanning electron microscopy using gold sputter technique. The particles were vacuum-dried, coated with gold palladium and observed microscopically.

\section{Optimization of plug}

The formaldehyde-treated insoluble capsule bodies were separated from the soluble caps. A quantity of the pellets, equivalent to $100 \mathrm{mg}$ of salbutamol sulphate, were weighed and filled into the insoluble capsule bodies manually, which were then plugged with baying quantities $(10,20$ and $30 \mathrm{mg})$ of various hydrophilic polymers (HPMC, HPC, PEO and sodium alginate) to provide a lag time of $2 \mathrm{~h}$. The polymer, in each case, was 
first compressed into a tablet in a hydraulic press (IR press, SV Scientific, Bangalore, India) and used as a plug. After insertion of plug, the cap and body of the capsule were sealed with $5 \%$ ethyl cellulose ethanol solution.

\section{Enteric coating of capsules}

The sealed capsules were dip-coated with 10 $\%$ w/w Eudragit L 100: S 100 dispersion in isopropyl alcohol containing $10 \%$ triethyl citrate and $5 \%$ talc as plasticizer and antitack agent, respectively. Different concentration of Eudragit S100, L100 and their various combinations $(1: 1,2: 1$ and $4: 1)$ were studied. The capsules were removed from the dispersion when the coat build-up level reached 4,6 and $8 \% \mathrm{w} / \mathrm{w}$ and observed for coat uniformity, pores and cracks under microscope.. Coating level was determined as $\%$ weight gain of the capsule. The capsules were dried initially at room temperature for $30 \mathrm{~min}$ and then in a hot air oven at $40{ }^{\circ} \mathrm{C}$ for $24 \mathrm{~h}$. After drying the capsules, they were subjected to disintegration test in $0.1 \mathrm{M} \mathrm{HCl}$ for $2 \mathrm{~h}$ to determine the ability of the coat to withstand acid environment. Thereafter, the capsules were again subjected to microscopic examination to check for the integrity of the coat. The enteric coated capsules which passed the disintegration test were further evaluated for coating integrity in $\mathrm{pH} 5.5$ since dissolution of coating in $\mathrm{pH}$ lower than 6.8 may alter the required lag time. On the basis of solubility in pH 5.5 buffer, coating compositions and levels that fell short were rejected to avoid alteration of lag time. Only coating levels and compositions which were not dissolved at all or dissolved very slowly in $\mathrm{pH} 5.5$ buffer were selected for further optimization of the most suitable enteric coating layer for pulsatile capsule.

\section{In vitro release studies}

The in vitro dissolution profiles of the developed system was studied using USP 2 apparatus. The capsules were tied to the paddles with a cotton thread so that they remain immersed in the dissolution media. Dissolution was carried out in $0.1 \mathrm{M} \mathrm{HCl}$ for initial period of $2 \mathrm{~h}$ and then in phosphate buffer $\mathrm{pH} 6$ and in simulating intestinal fluid for a further $4 \mathrm{~h}$. The volume of the dissolution medium was $900 \mathrm{ml}$ with the rotation speed set at $50 \mathrm{rpm}$ and temperature at $37 \pm 0.5^{\circ} \mathrm{C}$. Samples $(15 \mathrm{ml})$ were pipette out from dissolution flask at predetermined intervals, filtered using $0.45 \mu \mathrm{m}$ membrane filter and analyzed spectrophotometrically (UV-VIS, Shimadzu, Japan) at $274 \mathrm{~nm}$. Simultaneously, withdrawn samples were also replaced with fresh buffer to maintain the sink condition throughout the dissolution study.

Based on the results obtained for in vitro release profile and the lag time shown by the different formulations, the one which produced a desired release behavior and definite lag time of $4 \mathrm{~h}$ would be chosen as optimized formulation and subjected to stability studies and in vivo studies

\section{Stability studies}

Stability studies were carried out to determine the effect of polymer or formulation additives on strength of drug as well and the physical stability of the formulation under accelerated storage conditions The optimized formulation was subjected to stability studies as per the $\mathrm{ICH}$ guidelines at $40{ }^{\circ} \mathrm{C} \pm 5{ }^{\circ} \mathrm{C}$ and $75 \% \pm 5$ $\% \mathrm{RH}$. Samples were withdrawn at days 30 , 60 and 90 and analyzed for drug content and dissolution by HPLC [17]. The amount of drug remaining in the formulation after the stated period of time was determined by calculating degradation constant. Dissolution studies were also carried out to determine the specific of lag time on storage.

\section{Statistical analysis}

For optimization studies on the plug material and coating level, ANOVA was performed. Differences were considered statistically significant at $p<0.05$. The results are 
reported as mean \pm standard deviation (S.D.).

\section{RESULTS}

\section{Cross-inking of hard gelatin capsule}

Hard gelatin capsules bodies were crosslinked with formaldehyde to make them insoluble. Solubility studies indicate that both untreated capsule bodies and caps dissolved within $20 \mathrm{~min}$. while formalin-treated capsules bodies remained intact after $24 \mathrm{~h}$.

Limit test carried out to determine the presence of free formaldehyde in the treated capsules show that the color intensity of the test solution was less than that of standard formaldehyde solution indicating that free formaldehyde present in the treated capsule was within permissible limit $(20 \mu \mathrm{g}$ free formaldehyde per 25 capsules).

\section{Physicochemical properties of pellets}

The pellets were prepared by extrusionspheronization technique. At a low spheronization speed $(800 \mathrm{rpm})$, irregular pellets were formed while at a higher speed (1100 rpm or higher), mixed distribution of pellets shapes including rods, spheres, dumbbell and agglomerates were observed. Extrudate spheronized at $1000 \mathrm{rpm}$ for $3 \mathrm{~min}$ produced more spherical spheres. On the basis of surface morphology and shape of the pellets, the best 5 formulations were selected from the test batches (Table 1).

\section{Optimized formulation}

The results of the optimization studies on the 5 selected pellet formulations, in terms of flow properties and particle size distribution, are shown in Tables 2 and 3, respectively.

On the basis of the data, formulation F4 was selected for the preparation of chronotherapeutic drug delivery system. Scanning electron microscopy revealed that F4 pellets had a smooth surface and a spherical shape (Figure 1) with a narrow particle size distribution.

The yield, flow rate and mean particle size of formulation F4 was $74.7 \%, 21.6 \mathrm{~g} / \mathrm{sec}$ and $890 \mu \mathrm{m}$, respectively while drug content was

Table 1: Composition and characteristics of five selected pellets formulations on the basis of good pellet appearance

\begin{tabular}{|c|c|c|c|c|c|c|c|c|c|c|c|c|c|}
\hline \multirow[b]{2}{*}{ Code } & \multicolumn{8}{|c|}{ Ingredient (mg) } & \multirow[b]{2}{*}{$\begin{array}{c}\text { Water } \\
\text { (ml) }\end{array}$} & \multirow{2}{*}{$\begin{array}{l}\text { Sph. } \\
\text { speed } \\
(\mathrm{rpm})\end{array}$} & \multirow{2}{*}{$\begin{array}{l}\text { Sph. } \\
\text { time } \\
\text { (min) }\end{array}$} & \multirow[b]{2}{*}{ Remark } & \multirow{2}{*}{$\begin{array}{c}\% \text { Yield } \\
\pm \text { SD }\end{array}$} \\
\hline & Drug & Av2 & Av1 & Lact & MCC & DCP & PVP & Ac & & & & & \\
\hline F 1 & 5 & 70 & - & 20 & - & - & 2 & 3 & 60 & 1000 & 3 & Sp, SS, Gf & $73.5 \pm 11.2$ \\
\hline $\mathrm{F} 2$ & 5 & - & - & - & 30 & 60 & 2 & 3 & 60 & 1000 & 3 & Sp, SS & $79.0 \pm 7.0$ \\
\hline F 3 & 5 & - & - & - & 70 & 20 & 2 & 3 & 60 & 1000 & 3 & Sp, SS & $76.8 \pm 7.1$ \\
\hline F 4 & 5 & - & 80 & 10 & - & - & 2 & 3 & 60 & 1000 & 3 & Sp & $74.7 \pm 4.8$ \\
\hline F 5 & 5 & - & 70 & 20 & - & - & 2 & 3 & 60 & 1000 & 3 & Spl & $66.8 \pm 7.3$ \\
\hline
\end{tabular}

Key: Av1 = Avicel PH101; Av2 = Avicel PH102; Lact = lactose; MCC = microcrystalline cellulose; DCP = dicalcium phosphate, $P V P=$ polyvinyl pyrrolidone; $A c-A c D i S o l, S P=$ spherical, $S S=$ smooth surface. $G F=$ good

Table 2: Flow properties of selected pellets

\begin{tabular}{lcccccc}
\hline Code & $\begin{array}{c}\text { Angle of } \\
\text { repose } \\
(\mathbf{0})\end{array}$ & $\begin{array}{c}\text { Aerated bulk } \\
\text { density }\left(\mathbf{g} / \mathbf{c m}^{\mathbf{3}}\right)\end{array}$ & $\begin{array}{c}\text { Tapped density } \\
\left(\mathbf{g} / \mathbf{c m}^{3}\right)\end{array}$ & $\begin{array}{c}\text { Hausner } \\
\text { ratio }\end{array}$ & $\begin{array}{c}\text { Carr's } \\
\text { index (\%) }\end{array}$ & $\begin{array}{c}\text { Friability } \\
(\mathbf{\%})\end{array}$ \\
\hline F 1 & 23.43 & 0.625 & 0.731 & 1.16 & 14.50 & 0.73 \\
F 2 & 38.66 & 0.514 & 0.688 & 1.28 & 25.29 & 0.82 \\
F 3 & 28.72 & 0.689 & 0.886 & 1.28 & 22.23 & 0.53 \\
F 4 & $\mathbf{2 6 . 6 3}$ & 0.757 & 0.898 & 1.18 & 15.70 & $\mathbf{0 . 3 2}$ \\
F 5 & 31.97 & 0.583 & 0.857 & 1.46 & 17.54 & 0.41 \\
\hline
\end{tabular}


Table 3: Particle size distribution selected formulations

\begin{tabular}{ccccccc}
\hline \multirow{2}{*}{ Code } & \multicolumn{5}{c}{ \% Retained on mesh sieve } & Mean particle size \\
\cline { 2 - 6 } & $\mathbf{1 1 8 0} \boldsymbol{\mu m}$ & $\mathbf{1 0 0 0} \boldsymbol{\mu m}$ & $\mathbf{8 5 0} \boldsymbol{\mu m}$ & $\mathbf{7 1 0} \boldsymbol{\mu m}$ & Pan & $\begin{array}{c}\text { M }) \\
\text { F 1 }\end{array}$ \\
& 3.34 & 34.30 & 45.57 & 16.79 & 0.25 & 914 \\
F 2 & 4.60 & 26.25 & 53.57 & 15.53 & 0.05 & 915 \\
F 3 & 7.40 & 21.54 & 68.57 & 2.45 & 0.05 & 886 \\
F 4 & $\mathbf{4 . 4 3}$ & $\mathbf{1 3 . 7 7}$ & $\mathbf{7 3 . 8 6}$ & $\mathbf{7 . 6 6}$ & $\mathbf{0 . 2 8}$ & $\mathbf{8 9 0}$ \\
F 5 & 4.93 & 16.77 & 69.86 & 8.16 & 0.28 & 898 \\
\hline
\end{tabular}

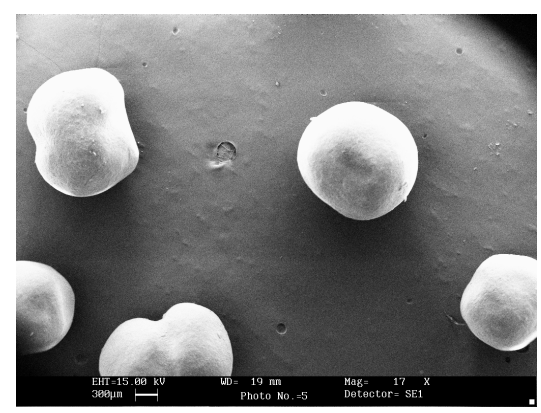

Figure 1: Scanning electron micrograph of optimized formulation (F4)

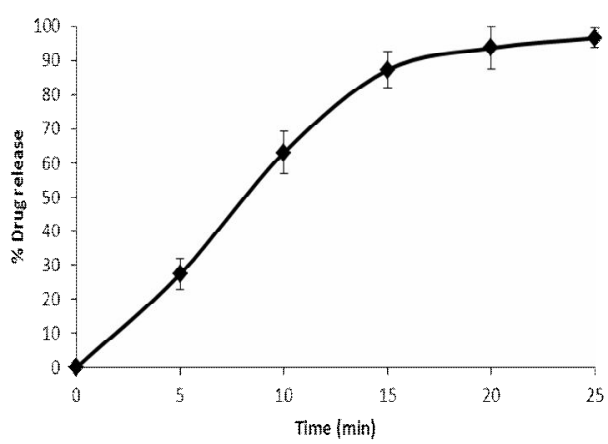

Figure 2: In vitro release profile of optimized pellet formulation (F4) in simulated intestinal fluid $(\mathrm{pH}$ 6.8)

$96.6 \%$. Fig 2 shows rapid drug release from this formulation in $\mathrm{pH} 6.8$ phosphate buffer, with approximately $90 \%$ released in $35 \mathrm{~min}$.

\section{Optimization of plug material}

The plug was aimed to delay the release for 2 $h$ after the dissolution of enteric layer in the intestinal environment. On the basis of amount of drug released at the end of $2 \mathrm{~h}$, plug ejection time (Table 4) as well as time taken to release $80 \%$ of drug from the system (Table 5), a suitable plug material capable of preventing drug release for the proposed period was selected from among those in Tables 4 and 5.

Table 4: Plug ejection time of various plug materials

\begin{tabular}{lccc}
\hline Plug & \multicolumn{3}{c}{ Plug ejection time (h) } \\
\cline { 2 - 4 } material & $\mathbf{1 0} \mathbf{~} \mathbf{g}$ & $\mathbf{2 0} \mathbf{~} \mathbf{g}$ & $\mathbf{3 0} \mathbf{~ g}$ \\
\hline HPC & $1.5 \pm 0.5$ & $3.0 \pm 0.4$ & $3.0 \pm 0.4$ \\
HPMC & $1.0 \pm 0.5$ & $3.0 \pm 0.3$ & $4.5 \pm 0.4$ \\
Na alginate & $0.8 \pm 0.3$ & $2.0 \pm 0.3$ & $3.5 \pm 0.5$ \\
PEO & $1.5 \pm 0.3$ & $3.0 \pm 0.4$ & $5.0 \pm 0.3$ \\
Guar gum & $0.5 \pm 0.5$ & $1.5 \pm 0.29$ & $2.5 \pm 0.3$ \\
\hline
\end{tabular}

Table 5: Time taken to release approximately $80 \%$ of the loaded dose $\left(D_{80 \%}\right)$

\begin{tabular}{lccc}
\hline \multirow{2}{*}{ Plug material } & \multicolumn{3}{c}{ Time (min) } \\
\cline { 2 - 4 } & $\mathbf{1 0} \mathbf{~ m g}$ & $\mathbf{2 0} \mathbf{~ m g}$ & $\mathbf{3 0} \mathbf{~ m g}$ \\
\hline HPC & 75 & 90 & 95 \\
HPMC & 50 & 90 & 180 \\
Na alginate & 45 & 120 & 180 \\
PEO & 75 & 150 & 195 \\
Guar gum & 30 & 75 & 75 \\
\hline
\end{tabular}

The results indicate that the best release profile was obtained with $20 \mathrm{mg}$ sodium alginate as plug (Figure 3 ).

Here again, the drug began to leach from the matrix prior to actual ejection but in a controlled pattern (initially slow but later on rapidly). In order to avoid leaching of drug before actual ejection of the plug, sodium alginate was blended with ethyl cellulose as a release modifier. The results obtained, shown 
in Fig 4, indicate lag times of 1.5 (3:1), 2.0 $(1: 1)$ and $3.5 \mathrm{~h}(1: 3)$. Formulation containing sodium alginate/ethyl cellulose blend in 1: 1 ratio as plug material showed a definite lag time of $2 \mathrm{~h}$ and a reduced early release of drug prior to actual ejection of plug. A complete burst effect was observed after a well-defined lag period. Consequently, it was chosen as optimum plug material for the proposed system.

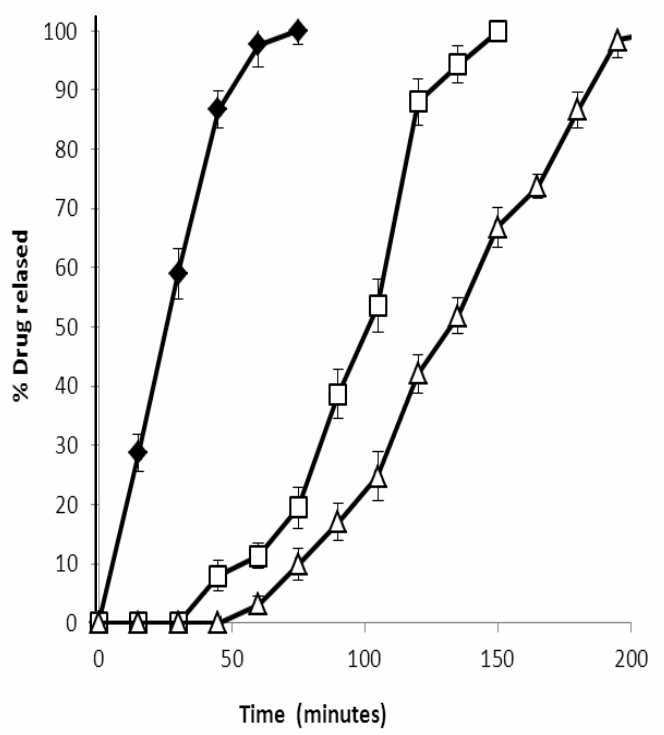

Figure 3: In vitro release profile of capsule plugged with different amounts of sodium alginate $(\bullet)=10 \mathrm{mg},(\square)=20 \mathrm{mg}(\Delta)=30 \mathrm{mg}$, of sodium alginate

After insertion of plug, capsules were fitted with soluble caps and the joint was sealed with $5 \%$ ethyl cellulose solution. Ethyl cellulose, due to its hydrophobic nature prevents entry of coating solution into the capsule during the coating process and prevents early drug release from the capsule. A significant difference was observed between all the formulation plugged with ethylcellulose/sodium alginate combination.

\section{Enteric coating of capsule}

Eudragit $S 100$ and L 100 singly or as blends of different ratios $(1: 1,2: 1$ and $4: 1)$ were used to coat the optimized capsule in order to determine the most suitable coating level. On the basis of disintegration and dissolution data, the most suitable combination of polymeric coating system and concentration was chosen. No pores and cracks were observed on coated capsule when subjected to microscopical examination.

In order to ensure the desired lag time of the developed capsule system was maintained, enteric coating layer was assumed to be dissolved only in the region of $\mathrm{pH}$ 6.8. Solubilization of enteric coating at $\mathrm{pH}$ below than 6.8 would have altered the desired lag time which eventually may lead to the failure of system in terms of drug release at appropriate time. Therefore, to determine the specificity of the coating layer, enteric coated capsule were subjected to solubility test in $\mathrm{pH}$ 5.5 and the coating layer which got dissolved in $\mathrm{pH} 5.5$ was rejected from the study.

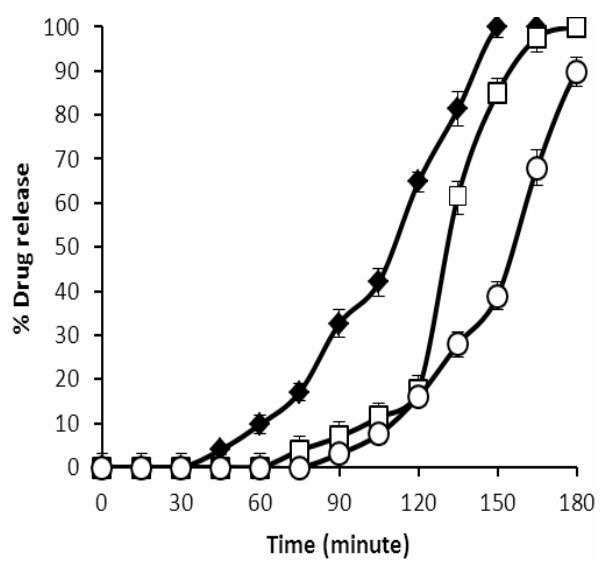

Figure 4: In vitro release profile of pulsatile capsule plugged with different amount of ethyl cellulose (EC) and sodium alginate (SA) mixture; $\bullet=15 \mathrm{mg} \mathrm{SA}$ and $5 \mathrm{mg} \mathrm{EC}, \square=10 \mathrm{mg} \mathrm{SA}$ and 10 $\mathrm{mg} \mathrm{EC}, \mathrm{o}=5 \mathrm{mg} \mathrm{SA}$ and $15 \mathrm{mg} \mathrm{EC}$

The capsule coated with $6 \%$ w/w Eudragit L100: S100 (1:4) or higher, did not dissolved in $\mathrm{pH} 5.5$ buffer, hence $6 \% \mathrm{w} / \mathrm{w}$ level was taken as the most suitable of all the formulations (Table 6). The coating slowly dissolved in $\mathrm{pH} 5.5$ and took $>2 \mathrm{~h}$ to get dissolved, by which time, the capsule would already be in 
Table 6: Effect of different Eudragit S100/L 100 ratios and coating levels on capsule disintegration and dissolution

\begin{tabular}{|c|c|c|c|c|c|c|c|c|c|c|c|c|c|c|c|}
\hline Parameter & & $\mathbf{S 1 0 0}$ & & & L 100 & & & $\begin{array}{l}00: L \\
(1: 1\end{array}$ & & & $\begin{array}{l}\text { Do: L } \\
(2: 1)\end{array}$ & & & $\begin{array}{l}00: L \\
(4: 1\end{array}$ & \\
\hline Coating level (\%w/w) & 4 & 6 & 8 & 4 & 6 & 8 & 4 & 6 & 8 & 4 & 6 & 8 & 4 & 6 & 8 \\
\hline Disintegration test & $\mathrm{F}$ & $\mathrm{P}$ & $\mathrm{P}$ & $\mathrm{F}$ & & & $\mathrm{F}$ & $P$ & $\mathrm{P}$ & $\mathrm{F}$ & $\mathrm{P}$ & D & $P$ & $\mathrm{P}$ & $P$ \\
\hline Solubility in $\mathrm{pH} 5.5$ & -- & $S$ & NS & -- & $S$ & $S$ & - & $S$ & $S$ & - & $S$ & $S$ & $S$ & NS & NS \\
\hline $\begin{array}{l}\text { Mean lag time at } \mathrm{pH} \\
6.8(\mathrm{~h})\end{array}$ & -- & 1.3 & 2.8 & -- & 1.3 & 1.3 & -- & 1.3 & 1.8 & - & 1.3 & & 1.9 & 2.0 & 2.3 \\
\hline
\end{tabular}

Key: $F=$ Failed, coating layer broken down or dissolved within $2 \mathrm{~h}$ in $0.1 \mathrm{M} \mathrm{HCl}, P=$ Passed coating layer was intact even after $2 \mathrm{~h}$ in $0.1 \mathrm{M} \mathrm{HCl}, S=$ Soluble, NS = Not soluble

the lower segment of the intestine where the $\mathrm{pH}$ is around 6.8, and hence lag time would not be affected.

A significant difference $(p<0.05)$ was observed for capsule coated with $4 \%$ and 6 $\% \mathrm{w} / \mathrm{w}$ of eudragit L100:S100 in a ratio of 1:4. But, there was no significant difference between the capsule coated with 6 and $8 \%$ $\mathrm{w} / \mathrm{w}$. Fig 5 shows the dissolution profile of the pellets incorporated in this coated capsule in $\mathrm{pH} 1.2$ and 6.8 media. Approx.97.7\% of the drug was released in $\mathrm{pH} 6.8$ within a period of $2.25 \mathrm{~h}$.

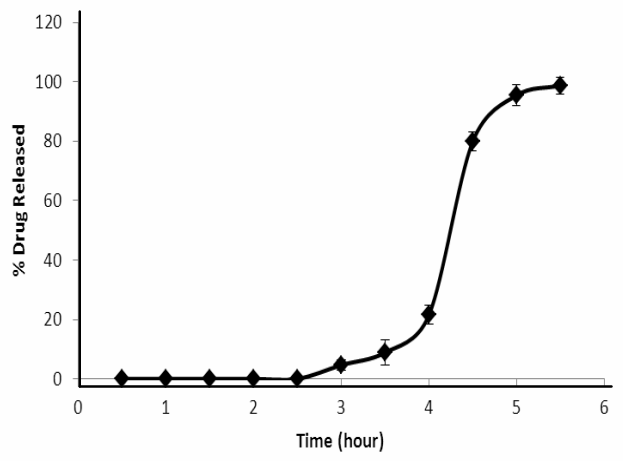

Figure 5: Dissolution profile of the final optimized capsule formulation in $0.1 \mathrm{M} \mathrm{HCl}$ (for the first $2 \mathrm{~h}$ ) and then in $\mathrm{pH} 6.8$ phosphate buffer.

\section{Stability study}

Drug content in the optimized formulation degraded by $3.26 \%$ (less than $5 \%$ ) in a period of three months suggesting that the formulation is stable on storage. Degradation constant was $20.7 \times 10^{-5}$. No alteration in lag time was observed based on dissolution studies carried out after the storage period, as per $\mathrm{ICH}$ guidelines

\section{DISCUSSION}

In order to modify the solubility of gelatin capsule bodies, Schiff's base condensation was employed. When gelatin capsule bodies were exposed to formalin vapors, the amino group present in the gelatin molecular structure undergoes cross-linking with the aldehyde group present in formaldehyde molecule, as per Schiff's base condensation, resulting in decreased aqueous solubility of gelatin [18].

Avicel $\mathrm{PH} 101$ in combination with lactose formed pellets with smooth surface characteristics. Increase in Avicel PH 101 content might have increased the plasticity of the pellets; and therefore can be easily deformed toa spherical shape during spheronization. Previous studies found that a mixture of Avicel PH101 and lactose in a ratio of $(80: 10)$ along with AcDiSol as superdisintegrant produced good pellets in terms of shape, flow property and release profile $[19,20]$. The pellets exhibited rapid drug release due probably to the presence of AcDiSol which acts as superdisintegrant and would have facilitated bursting of the pellets. Various hydrocolloids were evaluated in this study for the optimization of plug material plug to provide a $2 \mathrm{~h}$ lag time. With most of the material studied, sustained drug release behavior was observed instead of rapid release. This characteristic may be attributed 
to matrix formation, with the plug adhered to the capsule body even after the desired lag time. Nevertheless, better release profile was obtained with $20 \mathrm{mg}$ sodium alginate as a plug than with other polymers. However, drug leaching began prior to ejection of the plug and hence ethyl cellulose, which is hydrophobic, was used and this had a retarding effect on drug release. The formulation containing sodium alginate and ethyl cellulose (1: 1) as plug material showed a definite lag time of $2 \mathrm{~h}$ and a reduced early release of drug before actual ejection of plug. The plug was completely detached from the capsule body after the desired lag time due to less stickiness and weak mechanical strength of the matrix formed with sodium alginate/ethyl cellulose blend [21].

The proposed system was designed to release drug after $4 \mathrm{~h}$ lag time when the dosage form would probably be in the middle part of the small intestine where it would remain for a maximum period. In order to avoid the variability of gastric emptying and to prevent the start of drug release in stomach, the capsule was coated with Eudragit S100/L 100 since $\mathrm{pH}$-sensitive Eudragit polymers are ionized and solubilized in a range of $\mathrm{pH}$ rather than at a definite $\mathrm{pH}$. Since coating was aimed to dissolve at $\mathrm{pH} 6.8$ (middle part of the intestine), dissolution of coating material and drug release below or above this $\mathrm{pH}$ will ultimately shift the lag time. On the basis of disintegration in $0.1 \mathrm{M} \mathrm{HCl}$, and dissolution in phosphate buffer $\mathrm{pH} 5.5$ and $\mathrm{pH} 6.8$, most appropriate polymer ratio and level was selected. The enteric coat of Eudragit S100/L 100 (4:1) remained intact for $2 \mathrm{~h}$ in $\mathrm{pH} 1.2$, but dissolved at intestinal $\mathrm{pH}$ of 6.8. The soluble cap of the capsule had dissolved completely after $15-20 \mathrm{~min}$ and thus exposed the polymer plug which absorbed the surrounding fluid, swelled and released the drug through the swollen matrix. Following complete wetting of the plug, it might have formed a soft mass which was then easily ejected out of the capsule body, thus releasing the pellets into the medium which readily dissolved and complete drug release was achieved after a lag time of $4 \mathrm{~h}$.

\section{CONCLUSION}

Controlled pulsatile release of drug after a programmed $4 \mathrm{~h}$ lag period was achieved from cross-linked gelatin capsule shells containing salbutamol pellets, and sealed with a suitable mixture of sodium alginate and ethyl cellulose as plug. Thus, the developed capsule-based delivery system is a promising formulation for time-controlled delivery of salbutamol for the management of nocturnal asthma. However, in vivo studies are required to confirm the actual utility of the developed system.

\section{ACKNOWLEDGMENT}

The authors are thankful to University Grants Commission of India for providing financial assistance to carry out this work.

\section{REFERENCES}

1. Lemmer B. Chronopharmacology and controlled drug release. Expert Opin. Drug Deliv. 2005; 2(4): 667-681.

2. Levi F, Schibler U. Circadian Rhythms: Mechanisms and Therapeutic Implications. Annual Rev. Pharmacol. Toxicol. 2007; 47: 593-628.

3. Mandal AS, Biswas $N$, Karim KM, Guha $A$, Chatterjee S, Behera M, Kuotsu K. Drug delivery system based on chronobiology. J. Control. Rel. 2010; 147: 314-325.

4. Vianna EO. Mechanisms and Therapeutic Implications of Asthma Circadian Rhythm. Curr. Resp. Med. Rev. 2005; 13: 171-183.

5. Guinee DG, Dail. Hammar's Pulmonary Pathology: Nonneoplastic lung disease. New York: Springer: edn 3, 2008.

6. Baroffio M, Barisione G, Crimi E, Brusasco V. Noninflammatory Mechanisms of Airway Hyper-responsiveness in Bronchial Asthma: An Overview. Ther. Adv. Resp. Disease. 2009; 3(4): 163-174.

7. Richard JM, Schlegel SB. Chronobiology of Asthma. Am. J. Respir. Crit. Care Med. 1998; 158 (3): 1002-1007.

8. Pincus DJ, Beam WR, Martin RJ Chronobiology and chronotherapy of asthma. Clin Chest Med 1995; 16 (4): 699-713.

9. Pincus DJ, Humeston TR, Martin RJ. Further studies on the chronotherapy of asthma with inhaled steroids: the effect of dosage timing on 
drug efficacy. J Allergy Clin. Immunol. 1997; 100(6): 771-774.

10. Richard JM, Susan BS Chronobiology of asthma. Am. J. Resp. Crit. Care Med. 1998; 158: 10021007.

11. Gwen SS. Nocturnal asthma: mechanism and management. Mount Sinai J Med. 2002; 69: 140-147.

12. Li B, Zhu JB, Zheng CL, Gong W. A novel system for three-pulse drug release based on "tablets in capsule" device. Int. J. Pharm. 2008; 352(12): 159-164.

13. Takada K, Yoshikawa H. In: E Mathiowitz (Ed), Encyclopedia of controlled drug delivery, Willey, New York, 1999. pp 728-742.

14. Borgquist $P$, Nevsten $P$, Nilsson $B$, Wallenberg $L R$, Axelsson A. Simulation of the release from a multiparticulate system validated by single pellet and dose release experiments. 2004; 97 (3): 453-465

15. Morta R, Jose L, Vil J Design of new multiparticulate system for potential site specific and controlled drug delivery to the colonic region. J. Control. Rel. 1998; 55: 6777.

16. Mastiholimath VS, Dandagi PM, Jain SS, Gadad $A P$, Kulkarni AR. Time and $\mathrm{pH}$ dependent colon specific, pulsatile delivery of theophylline for nocturnal asthma. Int. J Pharm. 2007; 328: 49-56.

17. Sane RT, Gangal DP, Tendulkar RV, Kothurkar RM.,Ladage KD. HPLC method for determination of salbutamol sulphate. Ind. J. Pharma. Sci. 1990; 52: 197-199.

18. Philip AK, Philip B. Phase transited and vaporinduced dual capsular system (DCS) for achieving delayed and osmotic release of cefadroxil. Pharm. Dev. Tech. 2011; 16(5): 457-465.

19. Rudnic EM; Schwartz JB. Remington: The science and practice of pharmacy, Baltimore, USA: Lippincott Williams and Wilkins: edn 21, 2006; pp 889-917.

20. Rehman MA, Ali J. Development and in vitro Evaluation of Enteric Coated MultiparticulateSystem for Resistant Tuberculosis. Ind. J. Pharm Sci. 2008; 70(4): 477-481.

21. Roy $P$, Shahiwala $A A$. Multiparticulate formulation approach to pulsatile drug delivery: Current perspectives. J. Control. Rel. 2009; 134: 7480. 